\title{
Matocompetição em pastagem de Panicum maximum BRS Tamani
}

\author{
Weed competition in pasture of the Panicum maximum BRS Tamani \\ Competencia de malezas en pastos de Panicum maximum BRS Tamani
}

Recebido: 28/03/2021 | Revisado: 04/04/2021 | Aceito: 06/04/2021 | Publicado: 16/04/2021

\author{
Gustavo Silva de Oliveira \\ ORCID: https://orcid.org/0000-0002-9896-9156 \\ Instituto Federal de Educação, Ciência e Tecnologia Goiano, Brasil \\ E-mail: gustavosilvadeoliveira147@gmail.com \\ Leandro Spíndola Pereira \\ ORCID: https://orcid.org/0000-0003-0016-0330 \\ Instituto Federal de Educação, Ciência e Tecnologia Goiano, Brasil \\ E-mail: leandrop629@gmail.com \\ Gustavo Dorneles de Sousa \\ ORCID: https://orcid.org/0000-0003-2542-7409 \\ Instituto Federal de Educação, Ciência e Tecnologia Goiano, Brasil \\ E-mail: gustavodorneles7888@gmail.com \\ Jeovane Nascimento Silva \\ ORCID: https://orcid.org/0000-0002-1415-1825 \\ Instituto Federal de Educação, Ciência e Tecnologia Goiano, Brasil \\ E-mail: jeovaneagro@gmail.com \\ Estevam Matheus Costa \\ ORCID: https://orcid.org/0000-0003-4137-1222 \\ Instituto Federal de Educação, Ciência e Tecnologia Goiano, Brasil \\ E-mail: estevammcosta@yahoo.com.br \\ Adriano Jakelaitis \\ ORCID: https://orcid.org/0000-0003-0093-9846 \\ Instituto Federal de Educação, Ciência e Tecnologia Goiano, Brasil \\ E-mail: adriano.jakelaitis@ifgoiano.edu.br
}

\begin{abstract}
Resumo
Para a adoção de estratégias de manejo de plantas daninhas torna-se imprescindível o conhecimento dos períodos de interferência entre a comunidade infestante e a cultura de interesse econômico. Nesta pesquisa objetivou-se avaliar os efeitos da matocompetição na implantação da pastagem de Panicum maximum BRS Tamani e na rebrotação desta após o corte. Dois ensaios foram conduzidos em blocos ao acaso, com quatro repetições. No primeiro ensaio, a forrageira foi mantida em convivência com as plantas daninhas pelos períodos de $0,7,14,21,28,35,42,49,56$ e 63 dias após a emergência (DAE) da pastagem, e no segundo ensaio, a forrageira foi mantida sem a convivência das plantas daninhas pelos mesmos períodos até o corte da forrageira, aos 63 DAE. As parcelas foram mantidas livres da convivência de plantas daninhas por capinas manuais, conforme tratamento. A matocompetição se estabeleceu logo após a emergência da forrageira e reduziu o rendimento de forragem. O período crítico de prevenção da interferência de plantas daninhas na pastagem de P. maximum BRS Tamani situou-se entre 1(um) e se estendeu até aos 42 DAE. A interferência de plantas daninhas diminuiu a produção da forragem, bem como a porcentagem de cobertura vegetal, altura do dossel e perfilhamento da forrageira.
\end{abstract}

Palavras-chave: Comunidade infestante; Períodos de interferência; Rendimento de forragem.

\begin{abstract}
For the adoption of weed management strategies, it is essential to know the periods of interference between the weed community and the culture of economic interest. This research aimed to evaluate the effects of weed competition on the implantation of Panicum maximum BRS Tamani pasture and on its regrowth after cutting. Two trials were conducted in randomized blocks, with four replications. In the first trial, the forage was kept in contact with the weeds for periods of $0,7,14,21,28,35,42,49,56$ and 63 days after the emergence (DAE) of the pasture, and in the second trial, the forage was kept without the weeds living together for the same periods until the forage cut, at 63 DAE. The plots were kept free of weeds by manual weeding, according to treatment. Weed competition was established soon after the forage emergence and reduced the forage yield. The critical period for preventing weed interference in $P$. maximum BRS Tamani pasture was between 1 (one) and extended up to 42 DAE. Weed interference decreased the production of forage, as well as the percentage of vegetation cover, canopy height and forage tillering.
\end{abstract}

Keywords: Weed community; Periods of interference; Forage yield. 


\begin{abstract}
Resumen
Para la adopción de estrategias de manejo de malezas, es fundamental conocer los períodos de interferencia entre la comunidad de malezas y la cultura de interés económico. Esta investigación tuvo como objetivo evaluar los efectos de la competencia de malezas en la implantación de la pastura Panicum maximum BRS Tamani y en su rebrote después del corte. Se realizaron dos ensayos en bloques aleatorios, con cuatro repeticiones. En el primer ensayo, el forraje se mantuvo en convivencia con las malezas por períodos de $0,7,14,21,28,35,42,49,56$ y 63 días después de la emergencia (DLE) de la pastura. En el segundo ensayo, el forraje se mantuvo sin las malezas conviviendo durante los mismos períodos hasta el corte del forraje, a los 63 DLE. Las parcelas se mantuvieron libres de malezas mediante deshierbe manual, según tratamiento. La competencia de malezas se estableció poco después de la aparición del forraje y la reducción del rendimiento del forraje. El período crítico para la prevención de la interferencia de malezas en el pasto de P. maximum BRS Tamani fue entre 1 (uno) y se extendió hasta 42 DAE. La interferencia de malezas disminuyó la producción de forraje, así como el porcentaje de cobertura vegetal, la altura del dosel y el arado del forraje.
\end{abstract}

Palabras clave: Comunidad de malezas; Periodos de interferência; Rendimiento de forrajes.

\title{
1. Introdução
}

A pecuária brasileira é altamente dependente de pastagens para alimentação de rebanhos, visto que grande parte dos pecuaristas adotam o sistema de pecuária extensiva, caracterizada pela criação do rebanho em pasto, com a exploração de forrageiras principalmente do gênero Urochloa e Panicum (Machado et al., 2010; Inácio et al., 2018). Duas espécies forrageiras muito utilizadas são a Urochloa brizantha cv. Marandu e o Panicum maximum cv Mombaça, que embora apresentem pontos positivos, ainda possuem limitações como o baixo teor de proteínas e alta formação de talos, respectivamente.

Neste contexto, o programa de melhoramento genético da Empresa Brasileira de Pesquisa e Agropecuária (EMBRAPA) tem desenvolvido forrageiras mais produtivas, com maior teor de proteína e menor proporção de talos, como o caso do Panicum maximum cv. BRS Tamani, que apresenta alto valor nutritivo, alta relação folha/colmo, porte baixo, resistência a cigarrinha-das-pastagem e boa capacidade de rebrotação (Sousa; Martuscello, 2018; Braga; Jank, 2015).

Devido ao processo de melhoramento genético, as forrageiras lançadas recentemente e que possuem menor rusticidade, como é o caso de P. maximum cv. BRS Tamani, tendem a ser mais exigentes em diversos fatores, como a necessidade de adubação (Costa et al., 2004). Por outro lado, levanta-se a hipótese de que a mesma apresenta menor poder competitivo com plantas daninhas, quando comparada com outras forrageiras, como Urochloa brizantha cv. Marandu (Pereira et al., 2019).

As espécies cultivadas devem ser mantidas livres da interferência de plantas daninhas, para que possam expressar seu máximo potencial forrageiro, visto que a competição por recursos de crescimento exercidos pelas espécies infestantes, reduz o rendimento e onera os custos operacionais (Lins et al., 2019; Marques et al., 2019). O grau de interferência das plantas daninhas com a cultura cultivada depende de vários fatores ligados à comunidade infestante (composição específica, densidade e distribuição), a cultura (espécie, espaçamento e densidade de semeadura), do período de convivência e das condições ambientais (Pitelli, 2014).

Períodos de interferência correspondem ao intervalo durante o ciclo da espécie de interesse econômico em que não deve ocorrer a convivência de plantas daninhas para que não ocorra perdas significativas de produção. Os períodos são classificados em: período anterior a interferência (PAI), período de prevenção total da interferência (PTPI) e período crítico de prevenção da interferência (PCPI). O PAI é o período que se inicia com a emergência da planta cultivada e se estende até o dia em que a convivência com a comunidade infestante resulta em perdas significativas na produtividade. O PTPI é o período iniciado com a emergência da cultura e que se estende até a época em que a cultura teve que ser mantida na ausência de plantas daninhas para manifestação do seu potencial produtivo. O período que coincide com o limite superior do PAI e do PTPI é o PCPI, que é o período em que efetivamente as plantas daninhas devem ser controladas (Pitelli, 2000). 
Com base nisso, objetivou-se nessa pesquisa avaliar os efeitos da interferência de plantas daninhas sobre a implantação de pastagens de Panicum maximum BRS Tamani e sobre a capacidade de rebrotação desta após o corte.

\section{Metodologia}

Foram conduzidos dois ensaios em condições de campo entre novembro de 2018 e março de 2019 no Instituto Federal Goiano, em Rio Verde, Goiás, situado nas coordenadas 1748'25.1"S 5054'10.9"W. Segundo Köppen o clima da região é do tipo Aw mesotérmico, com duas épocas distintas, uma com chuvas e umidade (verão) e outra seca e fria (inverno). A precipitação total durante a condução do ensaio foi $811,6 \mathrm{~mm}$ e a temperatura média variou entre $25,1 \mathrm{a} 25,9{ }^{\circ} \mathrm{C}$.

A análise físico-química do Latossolo Vermelho distroférrico da área experimental apresentou pH 6,2 (SMP), Ca de 4,64 $\mathrm{cmol}_{\mathrm{c}} \mathrm{dm}^{-3}, \mathrm{Mg}$ de 2,50 $\mathrm{cmol}_{\mathrm{c}} \mathrm{dm}^{-3}, \mathrm{Al}^{3+}$ de 0,04 $\mathrm{cmol}_{\mathrm{c}} \mathrm{dm}^{-3}, \mathrm{H}+\mathrm{Al}$ de 4,5 $\mathrm{cmol}_{\mathrm{c}} \mathrm{dm}^{-3}$, CTC de 12,1 $\mathrm{cmol}_{\mathrm{c}} \mathrm{dm}^{-3}$ e K de $0,46 \mathrm{cmol}_{\mathrm{c}} \mathrm{dm}^{-3}$ e P (Melich) de 13,1 $\mathrm{mg} \mathrm{dm}^{-3}$, matéria orgânica de 3,62 $\mathrm{mg} \mathrm{dm}^{-3}$ e $\mathrm{Zn} \mathrm{4,5} \mathrm{mg} \mathrm{dm}{ }^{-3}$, saturação por bases de $62,8 \%$, saturação por alumínio de $0,5 \%$, argila de $64,5 \%$, silte $10,0 \%$ e areia de $25,5 \%$, na profundidade de 0 a $20 \mathrm{~cm}$.

A comunidade infestante do local avaliada antes da instalação dos ensaios foi caracterizada pela predominância de Alternanthera tenella (apaga fogo), Commelina benghalensis (trapoeraba), Cenchrus echinatus (capim-carrapicho), Nicandra physaloides (joá-de-capote), Digitaria insularis (capim-amargoso) e Eleusine indica (capim-pé-de-galinha). A comunidade infestante foi dessecada quimicamente com glifosato, na dose de $1.440 \mathrm{~g} \mathrm{ha}^{-1}$, em mistura com haloxyfope-p-metílico na dose de $62,35 \mathrm{~g} \mathrm{ha}^{-1}$.

Quinze dias após a dessecação foi feito o preparo convencional do solo por meio de duas arações e gradagens, e em seguida, foi realizado a abertura de sulcos com cultivador, com hastes espaçadas a $0,5 \mathrm{~m}$, e foi feita a semeadura manual da forrageira. A recomendação usada foi de 540 pontos de valor cultural (VC), semeadas na profundidade de $2 \mathrm{~cm}$, utilizando sementes incrustadas e certificadas (Sementes Santa Fé ${ }^{\circ}$ Ltda). A adubação de semeadura foi de $300 \mathrm{~kg} \mathrm{ha}^{-1}$ do formulado 0414-08 (N- $\left.\mathrm{P}_{2} \mathrm{O}_{5}-\mathrm{K}_{2} \mathrm{O}\right)$ e de cobertura foi de $80 \mathrm{~kg} \mathrm{ha}^{-1}$ de N, aplicados na forma de ureia.

Foram conduzidos dois ensaios com a forrageira P. maximum híbrido BRS Tamani, em delineamento em blocos casualizados, com quatro repetições. No primeiro ensaio, denominado grupo de convivência de plantas daninhas, a forrageira permaneceu em convivência com plantas daninhas por períodos iniciais crescentes de $0,7,14,21,28,35,42,49,56$ e 63 dias após a emergência (DAE) da forrageira, constituindo os tratamentos. As parcelas permaneceram livres da interferência de plantas daninhas por capinas manuais semanais após cada período de convivência. No segundo ensaio, denominado grupo controle de plantas daninhas, a forrageira foi mantida livre da interferência de plantas daninhas pelos mesmos períodos descritos acima, e as plantas daninhas que emergiram após estes períodos não foram mais controladas até o corte da forrageira. A área de cada parcela foi de $10 \mathrm{~m}^{2}$, representado por quatro fileiras, espaçadas a $0,5 \mathrm{~m}$, com cinco metros de comprimento.

Ao término de cada período de convivência foi realizado a coleta de plantas daninhas, por meio do lançamento ao acaso de dois quadrados amostrais vazados de $0,16 \mathrm{~m}^{2}(0,4 \times 0,4 \mathrm{~m})$ por parcela. Após a coleta das plantas daninhas no interior do quadrado foram efetuadas as contagens de indivíduos por espécie, as quais foram acondicionadas em sacos de papel, para determinação da massa seca. As plantas daninhas foram colocadas para secar em estufa de renovação e circulação de ar a $65^{\circ} \mathrm{C}$ por 72 horas, seguida de pesagem em balança analítica após secagem.

A área útil de coleta da forrageira foi de $1,5 \mathrm{~m}$ nas duas linhas centrais de cada parcela. As colheitas foram realizadas aos 63 DAE e aos 93 DAE, ou seja, aos trinta dias após o primeiro corte (30 DAC). A forrageira foi cortada com cutelo a 0,15 $\mathrm{m}$ do solo, e após o corte foi pesado a massa fresca da forragem colhida, retirando uma alíquota de $0,5 \mathrm{~kg}$ para determinação da massa seca. Dessa alíquota foram separados os colmos e as folhas, acondicionadas em sacos de papel e levadas para secagem em estufa de renovação e circulação de ar forçada a $65^{\circ} \mathrm{C}$, por 72 horas, ou até atingir massa constante, determinando-se, em 
seguida, as massas secas de folhas (MSF) e de colmos (MSC).

Antes de cada corte da forrageira, aos 63 DAE e aos 30 DAC, foi avaliada a altura do dossel (AD), com o auxílio trena graduada em centímetros, sendo realizada três medições por parcela. A porcentagem de cobertura foi avaliada por três avaliadores por meio de notas visuais da cobertura do solo pela forrageira, onde: $0 \%$ significou a ausência de cobertura do solo pela forrageira (forrageira morta) e 100\% equivaleu ao solo completamente coberto pela forrageira (Rizzardi; Fleck, 2004). Foi avaliado também a densidade de perfilhos por meio do lançamento de dois quadrados vazados de $0,16 \mathrm{~m}^{2}$, seguido da contagem do número de perfilhos (NP).

Os resultados obtidos foram submetidos às análises de variância e de regressão, adotando-se o nível de 5\% de significância. As determinações dos períodos de interferência (PAI, PTPI e PCPI) no primeiro corte (63 DAE) foram obtidas pela determinação da produção relativa dos tratamentos com interferência das plantas daninhas em relação à testemunha, admitindo 5\% de perdas aceitáveis do rendimento forrageiro.

\section{Resultados e Discussão}

Durante a condução dos ensaios observaram-se a ocorrência de dezoito espécies, distribuídas em onze famílias. Espécies pertencentes à família Poaceae foram mais predominantes, com destaque para Cenchrus echinatus (capimcarrapicho), Digitaria horizontalis (capim-colchão), Digitaria insularis (capim-amargoso), Eleusine indica (capim pé-degalinha), e Panicum maximum (capim colonião); seguida por Amaranthaceae: Alternanthera tenella (apaga-fogo), Amaranthus hybridus (caruru roxo); Euphorbiaceae: Euphorbia heterophylla (leiteiro) e Chamaesyce hirta (erva-de-santa-luzia); Asteraceae: Galinsoga parviflora (botão-de-ouro) Synedrellopis grisebachii (agriãozinho); Malvaceae: Sida cordifolia (guanxuma); Solanaceae: Nicandra physaloides (joá-de-capote); Commelinaceae: Commelina benghalensis (trapoeraba); Portulacaceae: Portulaca oleraceae (beldroega); Convolvulaceae: Ipomoea triloba (corda de viola); Phyllanthaceae: Phyllanthus tenellus (quebra-pedra) e Cyperaceae: Cyperus rotundus (tiririca). Nos ensaios de períodos de convivência e de controle de plantas daninhas a espécie de maior ocorrência foi Nicandra physaloides que representou 99,9\% e 93,2\% da comunidade infestante, respectivamente.

Na convivência entre a comunidade infestante e a cultura de interesse é importante verificar se há dominância de determinadas espécies, devido a habilidade competitiva diferenciada que determinadas espécies exercem sobre a cultura. Por exemplo, $N$. physaloides, se destaca principalmente devido ao alto porte que a espécie apresenta, o que promove sombreamento da cultura cultivada, reduzindo a capacidade fotossintética e a produção da cultura. Por outro lado, $N$. physaloides possui metabolismo $\mathrm{C}_{4}$, rápido crescimento inicial, elevada capacidade de acúmulo $\mathrm{d}$ emassa seca e rápida ocupação do nicho ecológico (Matos, 2013). Na definição de períodos de interferência na cultura da soja, Nepomuceno (2007) observou que as espécies Alternanthera tenella, Bidens pilosa e Cenchrus echinatus foram altamente competitivas com a cultura. Pereira et al. (2019), em Rio Verde-GO, observaram para a forrageira Urochloa brizantha cv. Marandu, a maior interferência de $N$. physaloides.

Para a densidade de plantas daninhas observou-se comportamento quadrático dos valores obtidos nos períodos de convivência, mostrando aumento na densidade de plantas daninhas até os $17 \mathrm{DAE}$, atingindo valores de 652 indivíduos por $\mathrm{m}^{2}$ (Figura 1A). Nos períodos de controle, a densidade inicial de plantas daninhas foi maior na ausência de controle com queda significativa dos valores com o aumento destes períodos, atingindo $50 \%$ da resposta aos 4 DAE. A supressão da densidade da comunidade infestante exercido pelo sombreamento da forrageira quando ocorreu o controle estendeu até os 21 DAE (Figura 1A). Semelhantemente este efeito foi observado para a redução de massa seca de plantas daninhas determinada nos períodos de controle com a forrageira (1B). 
Este resultado deveu-se a ocupação do espaço pela forrageira, reduzindo a quantidade de recursos necessários para o crescimento das plantas daninhas, como luz e nutrientes (Figuras 1A e 1B) (Mota et al., 2017). Menores valores de massa seca e de densidade de plantas daninhas encontrados no ensaio de controle, mostram que a partir do momento em que se realiza o controle inicial da comunidade infestante se reduz o poder competitivo destas com a forrageira, resultando em menor massa seca e densidade, principalmente devido a supressão imposta pelo sombreamento (Figuras 1A e 1B). Em relação a massa seca de plantas daninhas observada nos períodos de convivência, observou ajuste de modelo sigmoidal, com aumento de 50\% na variável resposta aos 35 DAE, sendo o valor máximo obtido de 903,64 g m² (Figura 1B).

Jakelaitis et al. (2010) e Pereira et al. (2019), trabalhando com períodos de controle de plantas daninhas em $U$. brizantha cv. Marandu, observam crescimento inicial lento da forrageira, o que demonstra necessidade de controle de plantas daninhas nos momentos iniciais de sua fase fenológica. No entanto, quando comparado com os valores obtidos para $P$. maximum - híbrido BRS Tamani em relação à $U$. brizantha, observa-se maior suscetibilidade do Panicum à matocompetição, o que pode ser resultado da menor rusticidade desta forrageira (Costa et al., 2004). 
Figura 1. Densidade (A) e massa seca (B) de plantas daninhas em função dos períodos de convivência e de controle com a forrageira Panicum maximum - híbrido BRS Tamani.

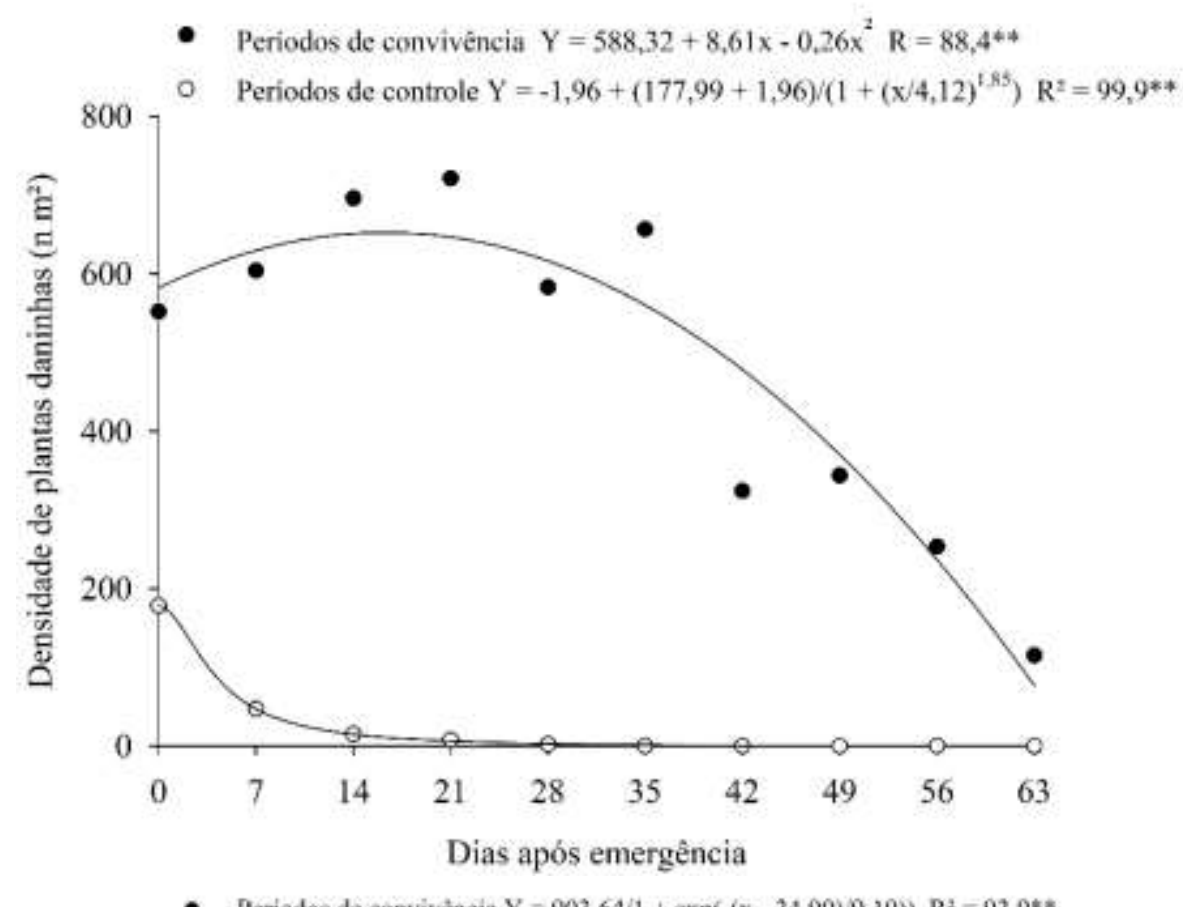

- Pcriodos de convivència $\mathrm{Y}=903,64 / 1+\operatorname{cxp}(-(\mathrm{x}-34,90)(9,19)) \mathrm{R}^{2}=93,9^{* *}$

Periodos de controle $\mathrm{Y}=-1,28+(100,54+1,28))\left(1+(\mathrm{x} / 6,62)^{2,44}\right) \mathrm{R}^{2}=99,8^{\text {a }}$

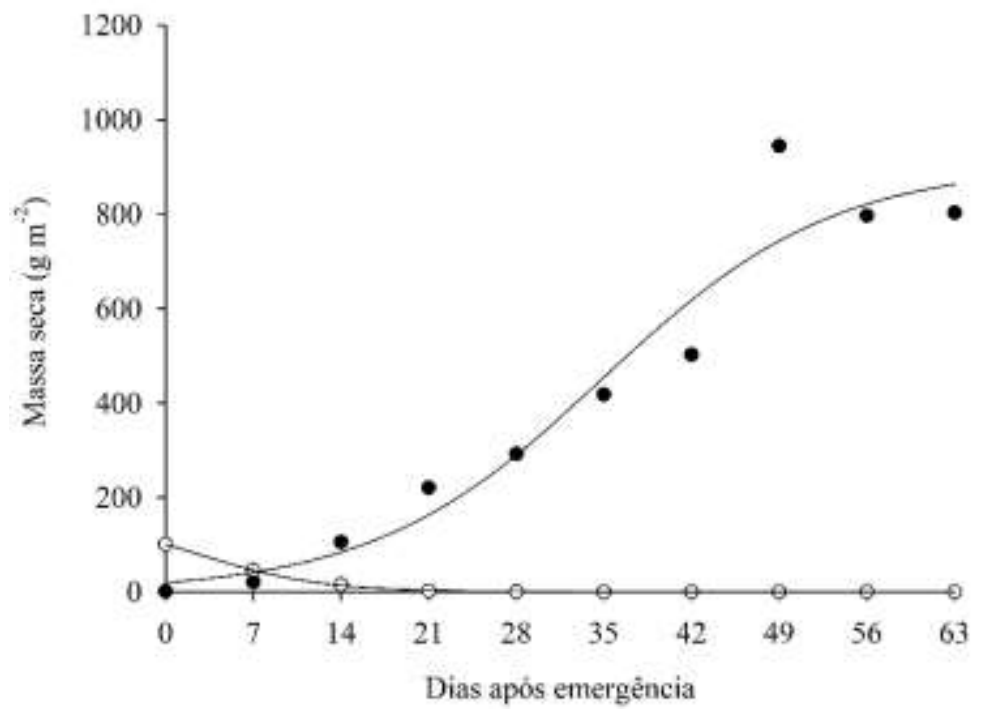

(B)

Fonte: Autores (2021).

A comunidade infestante interferiu nas variáveis avaliadas na forrageira, reduzindo a porcentagem de cobertura (PC), altura do dossel (AD), número de perfilhos (NP), massa seca de folhas (MSF) e massa seca de colmos (MSC) à medida que se intensificava a convivência das plantas daninhas com a forrageira (Tabela 1). 
Research, Society and Development, v. 10, n. 4, e42010414388, 2021

(CC BY 4.0) | ISSN 2525-3409 | DOI: http://dx.doi.org/10.33448/rsd-v10i4.14388

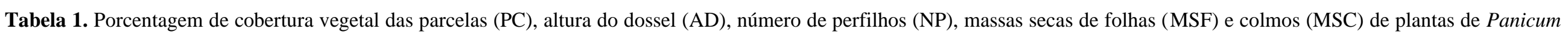
maximum - híbrido BRS Tamani nos períodos de convivência e de controle da comunidade infestante com a forrageira aos 63 dias após aa emergência (DAE).

\begin{tabular}{|c|c|c|c|c|c|c|c|c|c|c|c|c|}
\hline \multirow[t]{2}{*}{ Variáveis } & \multicolumn{10}{|c|}{ Períodos de convivência (DAE) } & \multirow[t]{2}{*}{ Equação } & \multirow[t]{2}{*}{$\mathrm{R}^{2}$} \\
\hline & 0 & 7 & 14 & 21 & 28 & 35 & 42 & 49 & 56 & 63 & & \\
\hline $\mathrm{PC}$ & 100,00 & 100,00 & 100,00 & 93,25 & 87,50 & 22,50 & 3,75 & 0,00 & 0,00 & 0,00 & $\widehat{\mathrm{Y}}=100,00 /(1+\exp (-(\mathrm{x}+32,10) /-8,41))$ & $99,8^{* *}$ \\
\hline $\mathrm{AD}(\mathrm{cm})$ & 90,87 & 86,87 & 86,25 & 72,62 & 62,37 & 32,25 & 13,25 & 0,00 & 0,00 & 0,00 & $\widehat{\mathrm{Y}}=88,70 /(1+\exp (-(\mathrm{x}-31,92) /-5,59))$ & $99,5^{* *}$ \\
\hline $\mathrm{NP}\left(\mathrm{n} . \mathrm{m}^{-2}\right)$ & 627,00 & 651,00 & 617,00 & 540,00 & 549,00 & 295,00 & 12,00 & 0,00 & 0,00 & 0,00 & $\widehat{\mathrm{Y}}=608,44 /(1+\exp (-(\mathrm{x}-34,63) /-2,72))$ & $99,0^{* *}$ \\
\hline $\operatorname{MSF}\left(\mathrm{kg} \mathrm{ha}^{-1}\right)$ & 4998,62 & 3627,81 & 3021,66 & 2732,30 & 1867,11 & 418,92 & 0,03 & 0,00 & 0,00 & 0,00 & $\widehat{\mathrm{Y}}=4998,62 /(1+\exp (-(\mathrm{x}+22,34) /-16,30))$ & $96,3 * *$ \\
\hline $\operatorname{MSC}\left(\mathrm{kg} \mathrm{ha}^{-1}\right)$ & 2122,30 & 1471,24 & 1389,18 & 839,10 & 299,63 & 38,61 & 0,01 & 0,00 & 0,00 & 0,00 & $\widehat{\mathrm{Y}}=2122,29 /(1+\exp (-(\mathrm{x}+17,98) /-12,69))$ & $97,8^{* *}$ \\
\hline \multirow[t]{2}{*}{ Variáveis } & \multicolumn{10}{|c|}{ Períodos de controle (DAE) } & \multirow[t]{2}{*}{ Equação } & \multirow[t]{2}{*}{$\mathrm{R}^{2}$} \\
\hline & 0 & 7 & 14 & 21 & 28 & 35 & 42 & 49 & 56 & 63 & & \\
\hline $\mathrm{PC}$ & 0,00 & 28,75 & 91,25 & 98,75 & 97,00 & 97,50 & 98,75 & 100,00 & 100,00 & 100,00 & $\widehat{\mathrm{Y}}=98,86 /(1+\exp (-(\mathrm{x}-8,84) / 2,04))$ & $99,9 * *$ \\
\hline $\mathrm{AD}(\mathrm{cm})$ & 0,00 & 60,00 & 83,00 & 84,88 & 84,63 & 84,50 & 85,25 & 85,63 & 87,63 & 89,83 & $\widehat{\mathrm{Y}}=85,68 /(1+\exp (-(\mathrm{x}-6,01) / 1,16))$ & $99,5^{* *}$ \\
\hline $\mathrm{NP}\left(\mathrm{n} . \mathrm{m}^{-2}\right)$ & 0,00 & 54,50 & 150,00 & 203,50 & 223,83 & 227,21 & 238,00 & 298,00 & 362,00 & 366,00 & $\widehat{\mathrm{Y}}=40,66+5,44 \mathrm{x}$ & $93,5 * *$ \\
\hline $\operatorname{MSF}\left(\mathrm{kg} \mathrm{ha}^{-1}\right)$ & 0,00 & 591,34 & 2651,32 & 4130,44 & 4162,82 & 4212,08 & 4146,06 & 4358,01 & 4094,08 & 4749,04 & $\widehat{\mathrm{Y}}=4298,85 /(1+\exp (-(\mathrm{x}-14,54) / 2,93))$ & $98,8 * *$ \\
\hline $\operatorname{MSC}\left(\mathrm{kg} \mathrm{ha}^{-1}\right)$ & 0,00 & 196,93 & 1233,13 & 1300,90 & 1629,35 & 1577,33 & 1856,04 & 1823,39 & 2083,74 & 1995,55 & $\widehat{\mathrm{Y}}=1863,81 /(1+\exp (-(\mathrm{x}-0,98) / 0,05))$ & $93,3 * *$ \\
\hline
\end{tabular}

** Significativo a $1 \%$ pelo teste F. Fonte: Autores (2021). 
No grupo de convivência observou ajuste do modelo sigmoidal de três parâmetros para a PC, AD, NP, MSF e MSC, explicando que 50\% das quedas dessas variáveis ocorrem aos 32, 31, 34, 22 e 18 DAE, respectivamente (Tabela 1). No grupo de controle de plantas daninhas, também houve ajuste de modelo sigmoidal de três parâmetros para PC, AD, MSF e MSC, com incremento de 50\% dos valores das variáveis, a partir do controle da comunidade infestante até aos 8, 6, 14 e 1 DAE da forrageira, respectivamente. Já para o NP, observou aumento de 5,44 perfilhos por $\mathrm{m}^{2}$ por dia quando se manteve o controle de plantas daninhas ao longo do ciclo da forrageira, até os 63 DAE (Tabela 1).

A convivência da comunidade infestante até os 42 DAE da forrageira resultou em alto grau de interferência, promovendo a morte da forrageira, devido principalmente a competição por recursos de produção (Tabela 1) (Durigan et al., 2018). A principal causa da morte da forrageira relaciona-se a predominância de $N$. physaloides na comunidade infestante, por apresentar metabolismo $\mathrm{C} 4 \mathrm{e}$ alto porte, resultando no sombreamento da forrageira. P. maximum - híbrido BRS Tamani de porte mais baixo e de metabolismo fotossintético C4 permanece suprimida e morre, quando sombreada (Matos et al., 2015).

Resultados semelhantes foram obtidos por Mota (2017) na avaliação de períodos de interferência de $P$. maximum cv. Massai, o qual observou menor produção de folhas e de colmos e perda da qualidade bromatológica em função da interferência imposta por plantas daninhas. Pereira et al. (2019), avaliando a interferência de plantas daninhas com $U$. brizantha cv. Marandu, também observaram redução da massa seca de folhas e colmos da forrageira, entretanto as perdas foram explicadas por modelos lineares, com redução de 14,13 e 17,62 $\mathrm{kg} \mathrm{ha}^{-1}$ da MSF e MSC, respectivamente, para cada dia de convivência com a comunidade infestante.

Os valores de produção relativa são apresentados na Figura 2, nas quais os valores de massa seca total dos tratamentos sem interferência de plantas daninhas equivaleram-se a $100 \%$ nos grupos de controle e de convivência. Desta forma, verificou a necessidade de controle da comunidade infestante a partir da emergência da forrageira, visto que a partir de 1 (um) DAE houve redução no rendimento de forragem, caracterizando o período anterior a interferência (PAI).

Figura 2. Produtividade relativa da forrageira Panicum maximum - híbrido BRS Tamani em resposta aos períodos de convivência e controle de plantas daninhas. Admitindo 5\% de perdas o PAI foi de 1 dia, o PTPI de 42 dias e o PCPI entre 1 e 42 dias após a emergência da forrageira.

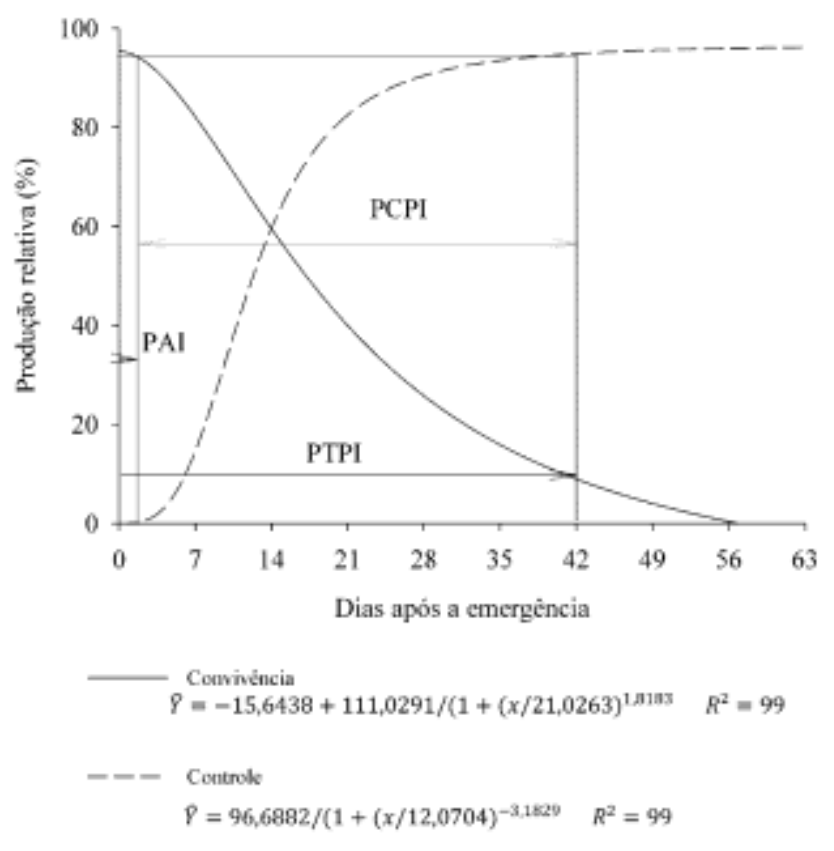

Fonte: Autores (2021). 
O PTPI da comunidade infestante com P. maximum - híbrido BRS Tamani estendeu-se até os 42 DAE, observando que a partir desse período a forrageira apresentou intenso crescimento vegetativo e foi capaz de exercer o controle de plantas daninhas pelo sombreamento. Para a produção relativa de P. maximum - híbrido BRS Tamani, observou incremento de 50\% quando o controle é feito até os 24 DAE (Figura 2), sendo que os valores máximos foram de 7.259 e $6.705 \mathrm{~kg}$ ha-1 nas testemunhas desprovidas de interferência nos ensaios de convivência e de controle, respectivamente. A convivência das plantas daninhas com a forrageira até os 42 DAE resultou em morte da forrageira (Figura 2). Dessa forma o PCPI foi de 1 DAE até os 42 DAE da forrageira.

Em trabalhos de matocompetição, Oliveira (2020) observou que o PCPI se situou entre 11 e 49 DAE de P. maximum cv. Massai. Jakelaitis et al. (2010) e Pereira et al. (2019) observaram o PCPI entre 9 e 26 DAE e 34 DAE, respectivamente, para $U$. brizantha cv. Marandu. De forma geral, observa-se que P. maximum - híbrido BRS Tamani apresenta maior intervalo de tempo de PCPI do que P. maximum e $U$. brizantha cv. Marandu, demonstrando menor rusticidade em relação a interferência da comunidade infestante.

A ausência de controle de plantas daninhas durante a formação de pastagem de P. maximum - híbrido BRS Tamani, interferiu negativamente em sua capacidade de rebrota (Tabela 2). Aos 30 DAC, ou 106 DAE, verificou redução de PC, AD, NP, MSC e MSF, em função da convivência e da ausência de controle de plantas daninhas (Tabela 3). Similarmente ao observado durante a implantação da pastagem, houve ajuste de modelo sigmoidal de três parâmetros para PC, AD, MSC e MSF. Em convivência com as plantas daninhas, houve redução de 50\% das variáveis respostas PC, AD, MSC e MSF a partir dos 41, 46, 40 e 39 DAE, respectivamente. Por outro lado, quando o controle é realizado o incremento de 50\% nas variáveis respostas foram aos 6, 8, 8 e 11 DAE, respectivamente (Tabela 2). Para o NP houve resposta linear para os grupos de convivência e de controle, sendo observado redução de 14,30 perfilhos por $\mathrm{m}^{2}$, a partir de cada dia de convivência da comunidade infestante e incremento de 8,37 perfilhos por $\mathrm{m}^{2}$, em função de cada dia de controle (Tabela 2). Jakelaitis et al. (2010), Mota (2017), Pereira et al. (2019) e Oliveira (2020) também observaram redução na capacidade de rebrotação da pastagem que conviveu com plantas daninhas. 
Research, Society and Development, v. 10, n. 4, e42010414388, 2021

(CC BY 4.0) | ISSN 2525-3409 | DOI: http://dx.doi.org/10.33448/rsd-v10i4.14388

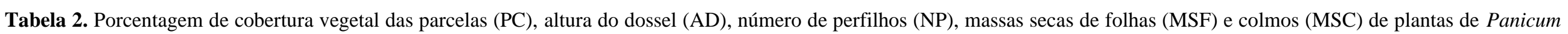

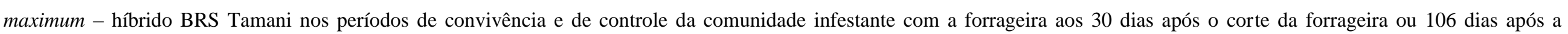
emergência (DAE).

\begin{tabular}{|c|c|c|c|c|c|c|c|c|c|c|c|c|}
\hline \multirow{2}{*}{ Variáveis } & \multicolumn{10}{|c|}{ Períodos de interferência (DAE) } & \multirow{2}{*}{ Equação } & \multirow{2}{*}{$\mathrm{R}^{2}$} \\
\hline & 0 & 7 & 14 & 21 & 28 & 35 & 42 & 48 & 56 & 63 & & \\
\hline $\mathrm{PC}$ & 100,00 & 100,00 & 100,00 & 100,00 & 97,50 & 81,25 & 43,33 & 16,25 & 0,00 & 0,00 & $\widehat{\mathrm{Y}}=100,57, /(1+\exp (-(\mathrm{x}-41,05) /-4,25))$ & $99,0 * *$ \\
\hline $\mathrm{AD}(\mathrm{cm})$ & 68,19 & 68,50 & 64,25 & 68,17 & 68,00 & 58,25 & 49,67 & 24,13 & 0,00 & 0,00 & $\widehat{\mathrm{Y}}=66,81 /(1+\exp (-(\mathrm{x}-46,10) /-3,95))$ & $99,8 * *$ \\
\hline $\mathrm{NP}\left(\mathrm{n} \cdot \mathrm{m}^{-2}\right)$ & 873,00 & 669,00 & 668,00 & 628,00 & 500,00 & 344,00 & 222,67 & 147,00 & 0,00 & 0,00 & $\widehat{\mathrm{Y}}=855,63-14,30 \mathrm{x}$ & $97,4 * *$ \\
\hline $\operatorname{MSF}\left(\mathrm{kg} \mathrm{ha}^{-1}\right)$ & 1971,63 & 2023,21 & 1843,17 & 2036,13 & 2165,18 & 1310,40 & 839,74 & 355,21 & 0,00 & 0,00 & $\widehat{\mathrm{Y}}=2019,67 /(1+\exp (-(\mathrm{x}-40,05) /-4,78))$ & $97,5^{* *}$ \\
\hline $\operatorname{MSC}\left(\mathrm{kg} \mathrm{ha}^{-1}\right)$ & 561,55 & 488,10 & 491,56 & 474,29 & 474,89 & 339,16 & 184,70 & 68,00 & 0,00 & 0,00 & $\widehat{\mathrm{Y}}=512,48 /(1+\exp (-(\mathrm{x}-38,84) /-5,17))$ & $98,9 * *$ \\
\hline \multirow{2}{*}{ Variáveis } & \multicolumn{10}{|c|}{ Períodos de controle (DAE) } & \multirow{2}{*}{ Equação } & \multirow{2}{*}{$\mathrm{R}^{2}$} \\
\hline & 0 & 7 & 14 & 21 & 28 & 35 & 42 & 48 & 56 & 63 & & \\
\hline $\mathrm{PC}$ & 0,00 & 63,75 & 87,50 & 100,00 & 100,00 & 100,00 & 100,00 & 100,00 & 100,00 & 100,00 & $\widehat{\mathrm{Y}}=98,66 /(1+\exp (-(\mathrm{x}-5,99) / 1,80))$ & $98,6^{* *}$ \\
\hline $\mathrm{AD}(\mathrm{cm})$ & 0,00 & 36,75 & 56,63 & 63,75 & 67,00 & 71,00 & 71,75 & 71,00 & 71,50 & 69,06 & $\widehat{\mathrm{Y}}=69,19 /(1+\exp (-(\mathrm{x}-7,43) / 3,33))$ & $97,4 * *$ \\
\hline $\mathrm{NP}\left(\mathrm{n} \cdot \mathrm{m}^{-2}\right)$ & 0,00 & 294,67 & 443,13 & 361,50 & 450,67 & 428,00 & 549,00 & 538,67 & 640,00 & 693,00 & $\widehat{\mathrm{Y}}=176,08+8,37 \mathrm{x}$ & $81,7 * *$ \\
\hline $\operatorname{MSF}\left(\mathrm{kg} \mathrm{ha}^{-1}\right)$ & 0,00 & 991,56 & 1947,08 & 1913,44 & 2061,34 & 2266,42 & 2161,59 & 2229,53 & 2365,52 & 2279,28 & $\widehat{\mathrm{Y}}=2183,82 /(1+\exp (-(\mathrm{x}-7,75) / 2,77))$ & $97,0 * *$ \\
\hline $\operatorname{MSC}\left(\mathrm{kg} \mathrm{ha}^{-1}\right)$ & 0,00 & 991,56 & 1947,08 & 1913,44 & 2061,34 & 2266,42 & 2161,59 & 2229,53 & 2365,52 & 2279,28 & $\widehat{\mathrm{Y}}=708,84 /(1+\exp (-(\mathrm{x}-10,96) / 2,79))$ & $96,8 * *$ \\
\hline
\end{tabular}

** Significativo a 1\% pelo teste de F. Fonte: Autores (2021). 


\section{Conclusão}

$\mathrm{Na}$ ausência de controle de plantas daninhas ocorre redução do rendimento de forragem e o comprometimento da capacidade de rebrota do pasto de P. maximum BRS Tamani.

O período crítico de prevenção da interferência de plantas daninhas para o Panicum maximum BRS Tamani estendese de 1 aos 42 DAE.

Novos ensaios sobre matocompetição com Panicum maximum BRS Tamani em diferentes condições edafoclimáticas e de manejo são recomendados para definição dos períodos de interferência e avaliação da intensidade de interferência de plantas daninhas com a forrageira.

\section{Agradecimentos}

Este estudo foi realizado com o apoio da Coordenação de Aperfeiçoamento de Pessoal de Nível Superior (CAPES), sob o código de financiamento 001 e do Instituto Federal de Goiano, Campus Rio Verde.

\section{Referências}

Braga, G., \& Jank, L. (2015). Performance of Nellore steers in Panicum maximum pastures. In: Embrapa Gado de Corte-Resumo em anais de congresso (ALICE). In: Reunião Anual Da Sociedade Brasileira de Zootecnia, 52., 2015, Zootecnia: otimizando recursos e potencialidades: Anais... Belo Horizonte: Sociedade Brasileira de Zootecnia.

Costa, N. L. Formação, manejo e recuperação de pastagens em Rondônia: Embrapa Rondônia, p. 219, 2004.

de Oliveira, G. S., de Sousa, G. D., Pereira, L. S., Costa, E. M., Silva, J. N., \& Jakelaitis, A. (2020). Interferência de plantas daninhas na implantação e rebrota de pastagem de Panicum maximum cv. Massai. Agrarian, 13(48), 178-186.

Durigan, J. C., Victoria Filho, R., Matuo, T., \& Pitelli, R. P. (1983). Períodos de matocompetição na cultura da soja (Glycine max (L.) Merril), cultivares Santa Rosa E IAC-2. I- Efeitos sobre os parâmetros de produção. Planta Daninha, 1(2), 86-100.

Inácio, M. C. P., Baldi, H. F., Santos, C. F., Oliveira, L. S., Ferreira, C. E. C., Rezende, R. M., \& Mendonça, A. T. (2018). Sistema intensivo x extensivo na criação de gado de corte. Revista da Universidade Vale do Rio Verde, 16(1), 1-9.

Jakelaitis, A., Gil, J. O., Simões, L. P., Souza, K. V., \& Ludtke, J. (2010). Efeitos da interferência de plantas daninhas na implantação de pastagem de Brachiaria brizantha. Revista Caatinga, 23(1) 8-14.

Lins, H. A., Souza, M. D. F., Albuquerque, J. R. T. D., Santos, M. G. D., Barros Júnior, A. P., \& Silva, D. V. (2019). Weed interference periods in sesame crop. Ciência e Agrotecnologia, 43, e000819.

Machado, L. A., Lempp, B., Valle, C. B., Jank, L., Batista, L. A. R., Postiglioni, S. R., \& Assis, G. M. L. (2010). Principais espécies forrageiras utilizadas em pastagens para gado de corte. Embrapa Pecuária Sudeste-Capítulo em livro científico (ALICE), 2010.

Marques, R. F., de Marchi, S. R., dos Santos Araújo, P. P., Pinheiro, G. H. R., Queiroz, B. B. T., \& Silva, A. A. S. (2019). Interferência de plantas daninhas na formação de pastagem com capim Vaquero. Acta Iguazu, 8(4), 107-120.

Matos, C. D. C., Silva, C. T., Cunha, P. T., Gandini, E. M. M., Silva, D. V., Barbosa, E. A., \& Ferreira, E. A. (2015). Crescimento de Nicandra physaloides em resposta à adubação com N, P e K. Semina: Ciências Agrárias, 36(3), 1307-1316.

Matos, C. da C. (2013). Crescimento e nutrição mineral de Nicandra physaloides (L.) Gaertn. 2013.62 p. Dissertação (Mestrado) - Programa de PósGraduação em Produção Vegetal, Universidade Federal dos Vales do Jequitinhonha e Mucuri, Diamantina.

Mota, R. V. (2017). Produtividade do capim Massai sob interferência de plantas daninhas em área de renovação. Jataí-GO: Universidade Federal de Goiás, 2017. 51p. Dissertação (Mestrado em Agronomia - Produção Vegetal), Universidade Federal de Goiás.

Nepomuceno, M., Alves, P. L. C. A., Dias, T. C. S., \& Pavani, M. C. M. D. (2007). Períodos de interferência das plantas daninhas na cultura da soja nos sistemas de semeadura direta e convencional. Planta Daninha, 25(1), 43-50.

Pereira, L. S., Jakelaitis, A., Oliveira, G. S., Sousa, G. D., Silva, J. N., \& Costa, E. M. (2019). Interferência de plantas daninhas em pastagem de Urochloa brizantha cv. Marandu. Revista Cultura Agronômica, 28(1), 29, 2019.

Pitelli, R. A. (2000). Estudos fitossociológicos em comunidades infestantes de agroecossistemas. Jornal Consherb, 1(2), 1-7.

Pitelli, R. A. (2014). Competição entre plantas daninhas e plantas cultivadas. In: Monquero, P. A. Aspectos da biologia e manejo das plantas daninhas: Rima, cap. 3, 61-81.

Rizzardi, M. A., \& Fleck, N. G. (2004). Métodos de quantificação da cobertura foliar da infestação de plantas daninhas e da cultura da soja. Ciência Rural, 34(1), 13-18. 
Research, Society and Development, v. 10, n. 4, e42010414388, 2021

(CC BY 4.0) | ISSN 2525-3409 | DOI: http://dx.doi.org/10.33448/rsd-v10i4.14388

Silva, H. P., Gama, J. D. C. M., Neves, J. M. G., Junior, D. D. S. B., \& Karam, D. (2010). Levantamento das plantas espontâneas na cultura do girassol. Revista Verde, 5(1), 162-167.

Souza, M. T. C., \& Martuscello, J. A. (2018). Produtividade de cultivares forrageiros no nordeste brasileiro. Revista Pubvet, 12(4), 1-9. 